\title{
Impacts of Climate Variability and Climate Change and Adaptation Strategy among Small Scale Farmers of Kurfa Chele District, East Hararghe Zone, Oromia Region, Ethiopia
}

\author{
Suleyman Abdureman Omer ${ }^{1} \quad$ Nuradin Abdi Hassen ${ }^{2}$ \\ 1.Technology Dissemination and Knowledge Transfer Officer, Research Extension and publication Office, \\ Institution of Haramaya University, Oromia Region, Ethiopia \\ 2.Lecturer and Researcher, Rural Development and Agricultural Extension Department, Institution of Haramaya \\ University, Oromia Region, Ethiopia
}

\begin{abstract}
Climate variability and change has caused instability in production and decline in productivity exacerbating food insecurity particularly in Latin America, Africa including Ethiopia and some parts of Asia. The magnitude and frequency of extreme climatic events is projected to increase. The effects of these climatic changes will become even more pronounced among small scale farmers whose farming activities are weather dependent and vulnerable to climate change, and already affected by environmental degradation and socio-economic risks. Effective adaptation to climate change among small scale farmers is therefore of critical importance, and is dependent on adoption of climate smart practices. However, studies have shown low adoption of climate smart farming practices among small scale farmers world over, in East Hararghe Zone and Kurfa Chele District. This study therefore examined factors influencing adoption of climate smart practices among farmers Kurfa Chele District, East Hararghe Zone, evaluated their existing knowledge, attitude and practice of these practices, assessed their perception of climate change, examined the extent of climate information dissemination, and the resultant impact on uptake of these practices. The research adopted a survey research design, where both quantitative and qualitative research strategies were used. Data was gathered through Focus Group Discussions, questionnaires, key informant interviews, observations and desk review. Both simple random and purposive sampling was used to sample 420 small scale farmers and technical officers of the agriculture sector respectively. Data was analysed using both quantitative and qualitative techniques. To test the statistical significance of the findings and relationships between the variables, chi-square test was used.
\end{abstract}

Keywords: Adaptation, adoption of climate smart practices, knowledge, attitude and practice, effect of climate change and Climate variability, climate information dissemination

DOI: $10.7176 / \mathrm{JBAH} / 10-21-03$

Publication date: November $30^{\text {th }} 2020$

List of Acronyms and Abbreviations

ALIN

ASARECA

ASDSP

CDM

CGIAR

CCAFS

CAADP

CSA

ENSO

EWIS

FAO

GoK

GDP

GCMs

GEF

GHGs

ICPAC

IFPRI

IPCC

Arid Lands Information Networks

Association for Strengthening Agricultural Research in Eastern and

Central Africa 
Agriculture Sector Development Support Programme

Clean Development Mechanism

Consultative Group on International Agricultural Research

Climate Change, Agriculture and Food Security

Comprehensive African Agricultural Development Programme

Climate Smart Agriculture

EL Nino Southern Oscillation

Early Warning and Information Systems

Food and Agriculture Organization

Government of Kenya

Gross Domestic Product

Global Climate Models

Global Environmental Facility

Greenhouse Gases

IGAD Climate Prediction and Application Centre

International Food Policy Research Institute

Intergovernmental Panel on Climate Change

\section{Introduction}

\subsection{Background of the Study}

Climate variability and change are among the major environmental challenges of the 21 st century. Successive reports of the Intergovernmental Panel on Climate Change (e.g. IPCC, 2007) and various other studies (e.g. Leemans and Eickhout, 2004; Morton, 2007; Cooper et al., 2009; Schlenker and Lobell, 2010; Thornton et al., 2011) show that climate change is having multifaceted effects on human societies and the environment. Scientific evidence indicates that anthropogenic factors are the major contributors to the prevailing global climate change (Forster et al., 2007).

Climate variability and change impacts directly or indirectly on all economic sectors to some degree, but agriculture is among the sectors most sensitive and inherently vulnerable to climate variability (Boko et al., 2007; Müller et al., 2011; Wheeler and Braun, 2013), and climate change is most likely to increase this vulnerability (Haile, 2005; Challinor et al., 2007b; Cooper et al., 2008; Thornton et al., 2010). The impacts of increased temperature from global warming and changes in rainfall patterns resulting from climate change are expected to reduce agricultural production and put further pressure on marginal land (Lobell and Field, 2007; Van de Steeg et al., 2009).

Agriculture sector is vital in eradication of extreme poverty and hunger, and supports livelihoods of close to 1.5 billion people worldwide living in smallholder households in rural areas (World Bank, 2008). Despite its vital importance, the sector is highly sensitive and susceptible to climate change and variability (Perret, 2006; Fischer et al., 2005; Van de Steeg et al., 2009; Schlenker \& Lobell, 2010), and small scale farmers are disproportionately affected, as a result of poverty, high dependency on natural resources and inadequate capability to adopt new livelihood strategies (Osbahr \& Viner, 2006).

The climate has changed, is changing, and will continue to change regardless of what investments in mitigation are made (Joel and Anne, 1998). Climate impacts are being felt today and greater impacts are unavoidable tomorrow. There is also an emerging consensus that Eastern Africa, and particularly Ethiopia, is one of the most vulnerable regions regarding the impacts of climate variability and change (Slingo et al., 2005; Boko et al., 2007; Challinor et al., 2007b; Thornton et al., 2011).

The Ethiopia country seeks to achieve middle-income-country status by 2025 but needs to overcome various hurdles to do so, including the country's high vulnerability to climate change. Ethiopia's climate is highly variable, both spatially and temporally, and projections suggest that this variability will continue alongside rising temperatures. This has significant implications for efforts to reduce poverty and food insecurity, particularly for women, people living in drought- and flood-prone areas, and those who are dependent on crop production and pastoralism for their livelihoods. To address these challenges, and to achieve economic growth and prosperity, the country will need to reduce vulnerability in key sectors such as agriculture, water, and health, while also improving the adaptive capacity of poor individuals and communities. Through the introduction of its Climate Resilient Green Economy (CRGE) Strategy and efforts to integrate climate change into the national development strategy, Ethiopia has demonstrated strong political will to address climate change and its impacts through adaptation and mitigation measures (Echeverria, D and Terton, A. 2016).

Mitigation efforts to reduce the sources of or to enhance the sinks of green house gas (GHG) will take time and requires international cooperation. Adaptation, in contrast, can reduce climate-related risks in human-managed systems on regional and local scales, and often with a short lead time. However, its scope is generally limited to specific systems and risk types (Fussel and Klein, 2004). Therefore, adaptation is critical in developing countries 
(Hassan and Nhemachena, 2008). Among the Ethiopian regional states, Oromia is already vulnerable to extremes of climatic variability; and climate change is likely to increase the frequency and magnitude of some natural disasters and extreme weather events.

Kurfa chele is one of the most vulnerable Districts in Oromia region to climate variability and change. Climate variability and change poses a huge threat to farmers in the District due to their overwhelming reliance on smallscale agriculture. Land degradation and water shortages have become looming problems. According to information obtained from KWAO (2011) in Kurfa chele District agricultural production is frequently affected by climate related shocks. Climate variability also contributes to the occurrence of pest and insect infestations. Farmers in Kurfa chele District have been responding to climate variability and change through various strategies. But, there was no empirical data that substantiates or supports the existing adaptation strategies practiced by the farmers in research area. Therefore, these are the gaps of knowledge that this study intends to bridge.

\subsection{Statement of the Problem}

Climate change and variability has resulted into decline and instability in production worsening the existing food insecurity and poverty in developing countries. The effects of these climatic changes will become even more pronounced among small scale farmers, whose farming activities are weather dependent and vulnerable to climate change, and already adversely affected by environmental degradation and socio-economic risks (World Bank, 2008; Rao et al., 2011; Thornton et al., 2009; Van de Steeg et al., 2009; Schlenker et al., 2010). To ensure resilience, adoption of climate smart practices among small scale farmers is required. In spite of the vital role played by climate smart practices in not only enhancing resilience, but also increasing productivity, reducing greenhouse gas emissions, and addressing environmental degradation, their adoption by small scale farmers has been low globally (FAO, 2010; FAO, 2013; Fanen et al., 2014). This is due to several lapses and challenges that have not been explored (Dance \& Sarpong, 2011; Roncoli et al., 2009; Adger et al., 2007). Most studies tend to focus on the impact of climate change on agriculture and adaptation measures (Mburu, 2013; Rao et al., 2011; Schlenker et al., 2010; Van de Steeg et al., 2009; Sivakumar et al., 2005), but few have examined the factors that affect the adoption of adaptation methods (Deressa et al., 2009).

Agriculture in East and Central Africa contributes about 40\% of the region's GDP and is the main livelihood source for approximately $80 \%$ of the population in the region (IFPRI, 2004). However, high variability of rainfall both within and between seasons across the region has caused uncertainty and large fluctuations in farmers' yield and income. This has been compounded largely with semi to arid conditions, degrading soils and high poverty (Fischer et al., 2005; IPCC, 2007a). The region undergoes protracted and extremely adverse droughts that cover expansive areas once every decade and more regular localized events (Christensen et al., 2007).

While farmers strive to adapt through innovation, studies by Rao et al., (2011) and Pettengell, (2010) indicated their limited capability to effectively respond to these rapid and overwhelming changes beyond their normal experience. In response to these unpredictable changes in the agriculture sector and particularly among small scale farmers, several approaches have been suggested among them being "Climate Smart Agriculture". This is agriculture that enhances productivity in a sustainable way, improves resilience, mitigates greenhouse gases, and boosts realization of national food security and development objectives (FAO, 2010; FAO, 2013).

This approach involves practices such as adoption of climate tolerant varieties, risk insurance and use of climate information in farming. These practices are mainly aimed at both sustainability and agricultural intensification, considered key for ensuring enhanced productivity and food security.

A study by Mutinda et al. (2010) indicated low awareness of climate change and its effects at community level, with farmers having difficulties distinguishing between impacts arising from climate change and those as a result of environmental degradation. Several studies (Brooks et al., 2005; Deressa et al., 2009; Dulal et al., 2010; Mburu, 2013) have been undertaken to measure the impact of climate change on Ethiopia agriculture, and suggested adaptation measures. However, most of them failed to indicate the factors affecting the choice of the suggested adaptation methods. This presents an important limitation since farmers' responses to climate change or their choice of adaptation methods is dictated by a host of factors.

Rogers (2003) affirms the importance of knowledge about technologies and attitude as important prerequisites that determine the decisions and actions of farmers in the course of adopting technologies or practices. In occasions where adoption of technologies has failed, several studies (Howley et al., 2012; Dzanku et al., 2011; Jones et al., 2010; Roncolli et al., 2009), have indicated limited knowledge as one of the factors responsible, but failed to show the specific knowledge gaps and why.

Availing timely and appropriate climate information has been considered critical in helping farmers prepare and adapt to uncertainties and risk through adoption of appropriate practices. In addition, innovation diffusion paradigm postulates that information dissemination is the main determinant that influences adoption of technologies; however, few studies (Murgor, 2014; Cherotich et al., 2012) have explored the extent of dissemination and access of weather and climate information among small scale farmers including the study area. There is therefore need to assess the extent of outreach of this information and its influence on adoption of climate 
smart practices, and dissemination pathways in order to determine appropriate measures for strengthening access and use of climate information for enhanced adoption of climate smart practices. Similarly, in response to effects of vagaries of weather attributed to climate change in Kurfa chele district, climate smart practices have been disseminated for several decades. In spite of these efforts, adoption of climate smart practices has also remained low among small scale farmers (ASDSP, 2014).

\subsection{Objectives of the research Study \\ 1.3.1 General Objective}

To improve understanding of impacts of climate variability and climate change and to explore adaptation strategies to reduce these climate-induced risks among small scale farmers of Kurfa chele district in the Eastern Hararghe Zone.

\subsubsection{Specific Objectives}

a) To analyze perception of climate change risks, their effects/ impact of climatic variability on farming and influence on adoption of climate smart practices among small scale farmers of studies area.

b) To determine the existing knowledge, attitude and practice of climate smart practices among small scale farmers of studies area.

c) To examine the extent of climate and weather information dissemination and its influence on adoption of climate smart practices among small scale farmers of studies area.

\subsubsection{Research Questions}

To achieve its objectives, the study was guided by the following research questions;

a) How is the perception of climatic change risks and their impacts on farming among small scale farmers influencing adoption of climate smart practices of studies area?

b) How is the existing knowledge and attitude towards influencing their adoption climate smart practices among small scale farmers of studies area?

c) To what extent has climate information been disseminated and influence adoption of climate smart practices among small scale farmers of studies area.

\section{Research Methodology}

\subsection{Description of the Study Area}

Kurfa Chele woreda is one of the twenty two woredas of East Hararghe zonal administrations in Oromia Regional State. It is located at a distance of $55 \mathrm{~km}$ from zonal town, Harar and $540 \mathrm{~km}$ from Addis Ababa. The woreda is bordered with Kersa woreda in the north, Haromaya and Fedis woredas in the east, Grawa and Bedeno woredas in the west and Grawa woreda in the south. The altitude of the woreda ranges from 1400 to 3400 meters above sea level (CSA, 2010). The same source indicated that the woreda falls in to high land, midland, and low land agro climatic zones. Total area of the woreda is 30,177 ha (KWARDO, 2015) or 259.69 square kilometer (CSA, 2010). Of its total area, $36 \%$ is high land, $13 \%$ is mid land and the remaining $51 \%$ is lowland. From the total coverage $11,894.84$-hectar is used for agricultural production, 6,746 hectare is covered by forest, 3817 hectare is used for grazing land, 2,905 hectare is arable land, and 4814.16 hectare is used for other purpose. Its annual average temperature varies between a maximum of $31 \mathrm{c} 0$ and a minimum of $10 \mathrm{c} 0$ with the annual rain fall ranges from $700 \mathrm{~mm}$ to $2000 \mathrm{~mm}$.

The woreda has a total population of 58,712 in 2007, and it is projected to be 75,939 in 2016 given a $2.9 \%$ annual growth rate of Oromia Region. From this population 37,557 are females and 38,382 are males, 90.2\% of the total population lives in the rural parts of the woreda and the remaining $9.8 \%$ of the population are urban dwellers (CSA, 2007). More than $98 \%$ of the woreda population makes their livelihood on agricultural activities (KWARDO, 2015). The main crop items of the woreda are cereals mainly sorghum and maize, in small areas wheat and barley, cash crops khat and coffee in low land, Irish potato in high land and green pepper in some small low land areas but size of farm land used for cash crop production is limited and their production system is rain fall dependent (KWARDO, 2015). Livestock keeping is also considered as subsidiary to the crop production activities. The same source indicated that, Kurfa Chele has twenty kebele administrative. Out of these two of them are small urban kebeles while the remaining eighteen are rural kebeles. In each kebele Agricultural extension workers and Health extension workers were assigned by the woreda Agricultural and Health offices respectively. According to the information obtained from the woreda Rural Road Authority, 10 rural and 2 urban kebeles were accessible for all weather roads while the remaining 8 rural kebeles were accessible only for dry season road.

In the study area, agricultural production is largely rain-fed in the face of erratic rainfall and frequent drought. The mean land holding per farm household is $0.5 \mathrm{Ha}$ in general and even less for high land and irrigable low land areas (KWARDO, 2015). 


\subsection{Study Design}

The research adopted a survey design involving both quantitative and qualitative research strategies. These research strategies facilitated triangulation and dovetailing of the findings and helped to offset the weaknesses of either of the two approaches (Bryman, 2008).

\subsection{Sample Size and Sampling Procedure}

The sample size for the study was arrived at by use of a formulae by Krejcie \& Morgan (1970). The formula entails determining the sample size(s), from a given fixed population(P) with the sample size within plus or minus 0.05 of the population proportion at 95 percent level of confidence. The $95 \%$ confidence level is preferred because its narrower, with lower variability and when coupled with a higher sample size it enhances precision (Bryman, 2008).

This formula is shown as follows:

$S=X^{2} N P(1-P) / d^{2}(N-1)+X^{2} P(1-P)$

Equation 2.1: Krejcie \& Morgan (1970)

Where: $X 2=$ Chi-Square table value for 1 degree of freedom at the preferred confidence level (in this case 3.84), $N=$ the population size (336 149), $P$ = the population proportion (assumed to be 0.5 ), $d$ - the degree of precision stated as a proportion (0.05). use of the formula gave 384 as the minimum sample size for the study.

However, the study adopted a sample size of 420 participants who were randomly selected from each of the 15 wards in the study area. The sample size was larger to accommodate non-responses. Both probability and nonprobability sampling techniques (simple random and purposive sampling) were used in this study. Simple random sampling technique was used in determining individuals for administration of questionnaires. The population was divided into sampling units represented by wards. Proportional sample sizes for wards was arrived at using the following formula.

$n i=\mathrm{n} / \mathrm{N}^{*} 420$

Where $\boldsymbol{n i}$ is Sample size for the ward, $\mathbf{n}$ is the total number of farmers in the ward and $\mathbf{N}$ is the total number of farmers in the study area. The respondents were randomly sampled from lists of farmers, who had been assigned numbers.

Purposive sampling was on the other hand, used in identifying key informants and Focus Group Discussions (FGDs) participants. In this study key informant interviewees were individuals who had competence and knowledge in the area of Agriculture and climate change by virtue of their academic qualifications and or many years of work, drawn from public and private agencies. While focus group participants, were mainly service providers (extension officers) and farmers who had working and farming experience in the area of study. They were also identified based on records of farmers and staff in the Agriculture and Livestock offices at the sub county level.

\subsection{Data Collection Methods}

Before the actual data collection, pretesting of tools to determine their reliability and validity using a randomly selected sample of 30 farmers and technical officers of agriculture was conducted. The farmers and technical officers were drawn from all the three sub counties of the study area. The study tools were considered reliable if the respondents answered the questions in the same way each time they were asked. The study tools were deemed valid, if they measured accurately the concepts; they were intended to measure (Bryman, 2008). The farmers and technical officers were taken through the questionnaire, key informant interview and focus group discussion tools and then asked to offer any suggestions and criticism regarding the clarity and appropriateness of each of the tools. After which, all of the recommendations and comments were taken into consideration and appropriate changes made (Bryman, 2008).

Data collection commenced with administration of individual questionnaires to small scale farmers who had been randomly selected for the study, after which key informant interviews were carried out with technical officers of in the agriculture sector. Collection of data was undertaken by supervisors who consisted of 3 agricultural officers and 4 research assistants from each ward, who were trained and served with questionnaires.

\subsubsection{Questionnaires}

The questionnaires were administered to 420 farmers selected randomly for the study. The questionnaire items were aligned to the four themes of the study. The questionnaires captured data on demographic and socioeconomic profile of respondents, their perception about climate change, its effects on farming and corresponding responses, knowledge, attitude and adoption of climate smart practices among the respondents, factors perceived to influence adoption and the institutional and policy context of adoption of climate smart practices. The questionnaires also captured the extent of dissemination of climate information and its impact on adoption of climate smart practices.

\subsection{Focus Group Discussions}

Four mixed sex Focus Group Discussions (FGDs) were undertaken, two with extension service providers from the agriculture sector, and the other two with farmers. These discussions, involved small groups of eight to twelve 
people who were led through open discussion guided by a trained leader (skilled moderator). During the discussions, the leaders explained to the participants the purpose of the discussions. After which the discussions were structured around a checklist of carefully predetermined questions under the four themes of the study. Apart from ensuring full participation of every participant, further probing was undertaken to ensure sufficient information was generated. The proceedings of the discussions were noted on flip charts and note books.

\subsubsection{Key Informant Interviews}

Key informant interviews were conducted with a broad array of actors drawn from public and private agencies with specific mandate in agriculture or climate change adaptation. The key informant interviews were aimed at providing an in depth understanding of climate change and its impacts in the study area, adoption of climate smart practices, policies and institutional arrangement at the county level dealing with climate change challenges. These interviews were also aimed at determining the technical and institutional capacity to respond to changing climate and its effects. During the study, thirty key informants were interviewed.

\subsubsection{Observations}

Observations were made to confirm and gain primary knowledge of climate smart technologies practiced in the study area. The observations were captured in field notebooks and in the form of pictures, and notes.

\subsubsection{Desk Study}

To identify institutional and policy weaknesses with regard to adoption of climate smart practices in the study area, a desk study was undertaken. The desk review included analysis of existing policies, strategies and regulations in the agriculture, water, environment and land both at National and Country levels.

\subsection{Type of Data Collected}

Both primary and secondary data were collected to realize the objectives of the study.

The data was encapsulated in four themes as indicated below.

a) Existing knowledge, attitude and practice of climate smart practices among small scale farmers.

b) Perception of climate change, its effects on farming and its impact on adoption of climate smart practices among small scale farmers.

c) Extent of climate and weather information dissemination and its influence on adoption of climate smart practices among small scale farmers.

\subsection{Data Analysis}

Data were analysed by use of both qualitative and quantitative approaches. The quantitative data mainly questionnaire items were coded and analysed using SPSS version 16.0, where the generated results were presented in form of tables, charts and figures. Qualitative data from key informant interviews, FGD notes and desk review of policies was analysed by establishing the categories and themes, relationships/patterns and conclusions drawn in line with the study objectives (Gray, 2004).

Table 2.1. Data Analysis Matrix

\begin{tabular}{|c|c|c|c|c|}
\hline Objective & Data Sets & Data Source & $\begin{array}{l}\text { Analysis } \\
\text { Method }\end{array}$ & $\begin{array}{l}\text { Statistical } \\
\text { Test }\end{array}$ \\
\hline 1 & $\begin{array}{l}\text { Knowledge, } \\
\text { Attitude and } \\
\text { Practice of } \\
\text { Climate Smart } \\
\text { Practices }\end{array}$ & $\begin{array}{l}\text { Questionnaires, Key } \\
\text { Informant Interviews, Focus } \\
\text { Group Discussions, Field } \\
\text { Observations }\end{array}$ & $\begin{array}{l}\text { SPSS, } \\
\text { Qualitative }\end{array}$ & Chi-square \\
\hline 2 & $\begin{array}{l}\text { Perception, } \\
\text { Climate } \\
\text { Change and Its } \\
\text { Effects, } \\
\text { Adoption of } \\
\text { Climate Smart } \\
\text { Practices }\end{array}$ & $\begin{array}{l}\text { Questionnaires, Key } \\
\text { Informant Interviews, Focus } \\
\text { Group Discussions, Field } \\
\text { Observations }\end{array}$ & $\begin{array}{l}\text { SPSS, } \\
\text { Qualitative }\end{array}$ & Chi-square \\
\hline 3 & $\begin{array}{l}\text { Climate and } \\
\text { Weather } \\
\text { Information } \\
\text { Dissemination, } \\
\text { Adoption of } \\
\text { climate smart } \\
\text { practices }\end{array}$ & $\begin{array}{l}\text { Questionnaires, Key } \\
\text { Informant Interviews, Focus } \\
\text { Group Discussions, Field } \\
\text { Observations }\end{array}$ & $\begin{array}{l}\text { SPSS, } \\
\text { Qualitative }\end{array}$ & Chi-square \\
\hline
\end{tabular}




\section{Results And Discussion}

\subsection{Perception of Climate Change Effects on Farming and its Influence on adoption of Climate Smart Practices}

The first objective of this study was to assess perception of climate change risks on farming among small scale farmers of the study area and its influence on adoption of climate smart practices.

\subsubsection{Perceived Climate Change}

Almost all respondents $(97.4 \%, \mathrm{n}=409)$ were in agreement that climate change was a reality. Similarly, majority $(63.1 \%, n=265)$ felt strongly that climate change was evident in the study area. This showed clearly the growing awareness of climate change challenge among farmers in the study area.

These findings were in agreement with several studies that had shown increasing awareness of farmers with regard to climate variability and change in Kenya and other parts of East and Central Africa in both drier areas and humid areas (Oremo, 2013; Legesse et al., 2012; Mburu, 2013; Kalungu et al., 2013; Nyanga et al., 2011). Interviews with key informants, particularly service providers in the agriculture sector indicated growing realization of climate change predicament.

In spite of the emerging appreciation of climate change concern, there were still other farmers, who still held the belief that the area was humid with adequate rainfall from both long rain and short rain seasons according to FGDs. There is therefore need for further sensitization to affirm and deepen their grasp of the climate change problem in the study area. Similarly, in spite of the glaring observation, analysis of County Government documents clearly demonstrated that most County Government officials were still oblivious of and not concerned about climate change (KCG, 2014). This was evidenced by lack of clear policy guidelines on climate change adaptation in agriculture. This implies that there is need for enhanced efforts towards creation of awareness on the causes and risks associated with climate change among the policy makers at the Country level.

\subsubsection{Perceived and Actual effects of Climate Change on Farming Activities}

Farmers cited different effects both in general and with regard to different aspects of climate change such as temperature, rainfall, change in rainfall patterns, droughts and floods.

In terms of general effects of climate change, most $(81.9 \%, n=344)$ of the respondents indicated inability to plan their farming activities and decline in crop yields $(11.2 \%, \mathrm{n}=47)$ as the main effects of climate change. Other effects of climate change cited included livestock deaths $(1.2 \%)$; destruction of crops and insufficiency of pastures $(1.7 \%)$. This showed that farmers were mostly being affected by shift in seasonal and erratic weather patterns, as shown by difficulties they were experiencing in planning. The findings also implied some element of flooding and drought occurrence in the Study Area as evidenced by destruction of crops, livestock deaths and insufficiency of pastures though to a small extent.

This study further affirms the findings at Yatta in Kenya, in Africa and other parts of the world, which showed decline in agricultural production and enhanced food insecurity as a result of climate change (Mendelsohn et al., 2000a; Boko et al., 2007; Mburu et al., 2014: Oromo, 2013). Key informants similarly indicated negative effects of climate change such as increased food insecurity, as a result of decline in food production. Other effects mentioned by key informants included increased leaching of nutrients and soil erosion as a result of surface runoff, and emergency of diseases such as Maize Lethal Necrosis Disease (MLND), Mites on Eucalyptus, and Tuta absolute pest on tomatoes.

With regard to effects of increase in temperature on farming, emergence of new strains of pests and diseases $(40.7 \%, \mathrm{n}=171)$, decline in crop yield $(24 \%, \mathrm{n}=101)$ and wilting of crops $(5.2 \%, \mathrm{n}=22)$ were the main effects which were cited. At the same time a significant number $(30 \%, n=126)$ of respondents showed unawareness with regard to the likely effects of temperature on farming activities (Table 3.1).

Table 3.1: Effects of Increased Temperature on Farming in the Study Area

Effects of increased temperature on $\quad$ Frequency $\quad$ Percentage
farming

(n)

\section{Emergence of new strains of pests and}

diseases

$\begin{array}{lll}\text { Decline in crop yield } & 101 & 24.0 \\ \text { Wilting of crops } & 22 & 5.2 \\ \text { I don't know } & 126 & 30\end{array}$

Total
$\%$
30

These results are consistent with IPCC report, which suggests that while temperate regions are likely to benefit in terms of crop yield as a result of increase in temperature, the tropical regions and semi-arid areas are likely to 
experience negative impacts such as decline in crop yield even with moderate rise in temperature of $1-2^{0} \mathrm{C}$. The report indicates possibility of all regions in the world experiencing negative impacts as a result of further upsurge in temperature by the end of $21^{\text {st }}$ Century (IPCC, 2007b).

In terms of effects of increase in rainfall and floods on farming, results showed that majority $(58 \%, n=242)$ of the farmers were not aware. Apparently flooding may not be common and hence low appreciation of its negative effects among the majority of farmers.

The effects, which were known to them as a result of increase in rainfall were soil erosion $(22 \%, n=94)$ probably due to the fact that the area is hilly and prone to soil erosion.

Other effects were noted, however, to a very limited extent. Decline in crop yield, destruction of crops, poor quality pasture as result of nutrient leaching and pests and diseases scored very low respectively $(6 \%, n=26),(4 \%$, $n=18),(4 \%, n=18),(3 \%, n=13)$. These findings on the overall showed low effects of enhanced rainfall that is normally accompanied by flooding in other areas. This is because of the hilly nature of the topography of the study area.

Compared to other climate change variables, the impact of irregular rainfall patterns was highly pronounced in the area. Almost all $(99.8 \%, \mathrm{n}=419)$ of the respondents underscored the negative effects of erratic rainfall patterns on farming. Majority $(70.5 \%, \mathrm{n}=296)$ identified decline in crop yield as the most serious effect, followed by inability to plan farming activities $(23.8 \%, \mathrm{n}=100)$ and instability in production $(5.5 \%, \mathrm{n}=23)$ (Table 3.2).

\section{Table 3.2: Effects of Erratic Rainfall Patterns on Farming in the Study Area

Effects of erratic rainfall Frequency Percentage
patterns

(n) $\quad \%$

\begin{tabular}{lll}
\hline Decline in crop yield & 296 & 70.5 \\
Inability to plan farming activities & 100 & 23.8 \\
Instability in production & 23 & 5.5 \\
No response & 1 & 0.2 \\
& & \\
\hline Total & 420 & 100.0
\end{tabular}

These results were in agreement with Huho et al. (2012), who affirmed changing rainfall patterns in Laikipia County with overall decline in growing period of crops and yield. Similar results were also obtained by Arukulem et al. (2015) at Senetwo Location in West Pokot County, who indicated reduced growing period, erratic planting dates, and overall decline in yield as a result of changing rainfall pattern. This showed the need to provide timely weather information to farmers to help them plan and mitigate the effects of erratic rainfall patterns.

\subsubsection{Farmers Degree of Perception and Concern about Climate Change effects on Farming}

In agreement with the above findings, majority $(97.3 \%, n=409)$ of farmers agreed that climate change had negatively affected their farming activities (Table 3.3). Similarly, $(54 \%, n=227)$ strongly felt climate change had serious implications on farming enterprises (Table 3.3).

Table 3.3 Farmers Degree of Perception about Climate Change Effects on Farming in the Study Area

$$
\text { Farmers degree of perception } \quad \text { Frequency } \quad \text { Percentage }
$$

(n) $\%$

\begin{tabular}{lll}
\hline Strongly agree & 227 & 54.0 \\
Agree & 182 & 43.3 \\
I don't know & 11 & 2.7 \\
& & \\
\hline Total & 420 & 100.0
\end{tabular}

On the other hand, shows that most $(92 \%, n=385)$ of farmers were concerned about climate change effects. Key informants attested to the concerns farmers had with regard to climate change that had been demonstrated by frequent visits of farmers seeking for information on adaptation to the changing conditions. These findings were in agreement with a study by Arbuckle et al. (2013) among Iowa farmers in the United States of America, who showed concern about climate change effects and pursuit of adaptation strategies to climate change. The high concern about climate change effects among farmers in the study area, therefore pointed to their serious need for adaptation hence adoption of climate smart practices.

\subsubsection{Adaptation to Climate Change effects}

Most $(74 \%, n=311)$ of the respondents acknowledged efforts towards mitigation of climate change effects. This revealed considerable emphasis on adaptation to climate change effects in the study area among the majority 
farmers.

However, majority $(72.5 \%, \mathrm{n}=305)$ could only indicate adaptation to climate change through adoption of appropriate crop and livestock varieties. Very few farmers thought of diversification to other non-farming activities $(1 \%)$, increased water conservation (3\%), varying planting date $(9 \%)$ and insuring of crops and livestock $(1 \%)$ as adaptation measures to climate change.

These results showed farmers high consideration of planting and rearing suitable varieties as key measure of adaptation to climate change. However, they demonstrated limited understanding of many other adaptation options such as agroforestry, insurance, water conservation etc. The results were also in congruence with several studies (Deressa et al., 2009; Legesse et al. 2012) in Ethiopia, which showed adoption of suitable varieties as one of the key response strategies to climate change effects. This is also in agreement with IPCC (2007a) which considers adoption of appropriate varieties of crops and livestock feeds such as finger millets, sorghum, groundnuts and wonder grass as a key element in combating the threat of climate change to food security. Key informant interviews with technical officers of Agriculture, also affirmed shift towards climate smart practices such as greenhouse and water harvesting technologies in response to perceived climate change among farmers.

\subsection{Farmers Knowledge, Attitude and Practice of Climate Smart Practices}

The second objective of this study was to determine the existing knowledge, attitude and practice of climate smart practices among small scale farmers of the Study Area. Adoption of agricultural innovations has been shown to depend on farmer's knowledge and attitude (Roger, 2003). It was therefore hypothesized that knowledge of climate smart practices among small scale farmers of the study area had significant influence on their adoption.

\subsubsection{Operational Knowledge of the Climate Smart Practices}

Majority $(85 \%, \mathrm{n}=357)$ of the respondents indicated dearth of working knowledge with regard to these practices, only a few $(15 \%, \mathrm{n}=63)$ acknowledged possession of operational knowledge (Table 3.8$)$.

Table 3.8: Operational Knowledge of Climate Smart Practices among

$$
\text { Small Scale Farmers in the Study Area }
$$

\begin{tabular}{lll}
\hline $\begin{array}{l}\text { Operational } \\
\text { knowledge }\end{array}$ & Frequency & Percentage \\
& (n) & $\%$ \\
\hline Yes & 63 & 15.0 \\
No & 357 & 85.0 \\
\hline Total & 420 & 100.0
\end{tabular}

This showed the enormous ground yet to be covered in terms of enhancing knowledge levels among these farmers, in order to promote adoption of climate smart practices. FGDs and Key informant interviews with farmers and technical officers affirmed limited understanding of the concept of climate smart practices not only amongst farmers but also extension service providers. These findings are in agreement and affirm the outcomes of several studies (Ajayi et al., 2006; Sanginga \& Woomer, 2009; McCarthy et al., 2011; Blanco \& Lal, 2008), which indicated knowledge as a fundamental constraint to adoption of agroforestry practices, pasture management and rehabilitation, intercropping, soil and water conservation structures, cover crops and improved fallows.

These findings were in congruence with the lessons learnt from a 3 year Mitigation of Climate Change in Agriculture (MICCA) pilot project in Kaptumo, Nandi County of Kenya, which promoted adoption of climate smart practices such as agroforestry, improved fodder production, tree nurseries, manure management, composting and biogas generation (FAO, 2015). At the end of the project it was apparent adoption of the select climate smart practices was constrained by lack of knowledge (FAO, 2015).

\subsubsection{Perceived Level of Knowledge of Climate Smart Practices among Farmers}

Among respondents $(15 \%)$, who had indicated as having knowledge of climate smart practices, very few of them had high (5.2\%) to very high (0.2\%) knowledge levels, majority (9.76\%) had low knowledge level. According to key informants, the low level of knowledge was attributed to inadequate knowledge on the part of extension service agents with regard to climate smart practices, lack of training materials and opportunities for learning climate smart practices and lack of explicit policy for implementation of climate smart practices. This explicitly showed that low level and lack of knowledge on climate practices, was a key factor constraining the adoption of climate smart practices in the study area. This was in agreement to the findings by FAO (2015) in Nandi County, Kenya and Fanen et al. (2014) in Northern Nigeria.

\subsubsection{Attitude towards Climate Smart Practices}

\subsubsection{Preference for Climate Smart Practices}

Most $(84.5 \%)$ farmers expressed enormous preference for the practices. FGDs affirmed the positive attitude amongst farmers concerning climate smart practices. This implies most farmers were willing to apply the practices, 
but are constrained by other factors such as lack of finances. These findings were in contrast with those of Margues et al. (2015) in central Spain, who found that most (68\%) farmers were unwilling to use cover crops to control soil erosion. This revealed the negative attitude attributed to lack of knowhow.

\subsubsection{Reasons for Preferring Climate Smart Practices}

Most (79.9\%) farmers considered climate smart practices favorably mainly because of their potential to contribute to increased income $(28.5 \%, \mathrm{n}=120)$, high productivity $(16.2 \%, \mathrm{n}=68)$, production $(24.5 \%, \mathrm{n}=104)$ and better planning of farming $(10.7 \%, \mathrm{n}=45)$ linked to use of agro weather information (Table 3.9). These results clearly showed that most farmers were more inclined to practices that enhanced income, productivity and production within the context of small land sizes in the study area. This affirmed the argument of Woelcke (2012) that farmers were more likely to adopt practices which contributed to increase in production and income.

Table 3.9: Reasons for Preference of Climate Smart Practices in the study area

\section{Responses}

\section{Frequency Percentage}

(n) $\%$

\begin{tabular}{lll}
\hline Increases productivity & 68 & 16.2 \\
Improves soil fertility & 29 & 6.9 \\
Enhances resilience to climate & 11 & 2.6 \\
change & & \\
Better planning of farm activities & 45 & 10.7 \\
Improves production & 104 & 24.8 \\
Increases income & 120 & 28.5 \\
Enhances food security & 16 & 3.8 \\
No preference & 27 & 6.4 \\
& & \\
\hline Total & 420 & 100.0
\end{tabular}

\subsubsection{Risks and Uncertainties of Adopting Climate Smart Practices}

Majority $(60.5 \%, \mathrm{n}=254)$ of the respondents, perceived adoption of climate smart practices as risky and uncertain, only $(39.5 \%, \mathrm{n}=166)$ viewed adoption of climate smart practices as posing either moderate or low risk at all (Table 3.10).

Table 3.10: Level of Risk of Adopting Climate Smart Practices in the study area

Level of risk of adopting Frequency Percentage

climate smart practices

(n) $\%$

\begin{tabular}{lll}
\hline High & 254 & 60.5 \\
Moderate & 163 & 38.8 \\
Low & 3 & 0.7 \\
& & \\
\hline Total & 420 & 100
\end{tabular}

This affirms the postulation that adoption of most innovations face uphill task in a population when it's first introduced, with only a few early adopters taking up the challenge because of risk averseness (Rogers, 2003). There were several perceived risks that respondents gave in relation to adoption of climate smart practices, however, high capital and labor requirement per unit area (61\%) and uncertain returns $(32.1 \%)$ featured prominently compared to others such season specificity of these technologies limiting economic benefit to certain type of seasons (6.9\%) (Table 3.11). This unequivocally shows high capital and labor requirement and uncertainty of returns constitutes the most serious risks that had hindered adoption of climate smart practices in the study area. 
Table 3.11: Risks of adopting Climate Smart Practices in the study area

\begin{tabular}{lll}
$\begin{array}{l}\text { Risks of adopting climate smart } \\
\text { practices }\end{array}$ & $\begin{array}{l}\text { Frequency } \\
\text { (n) }\end{array}$ & $\begin{array}{l}\text { Percentage } \\
\%\end{array}$ \\
\hline $\begin{array}{l}\text { Season specificity of these technologies } \\
\text { High requirement of labor }\end{array}$ & 29 & 6.9 \\
$\begin{array}{l}\text { and capital investments } \\
\text { Uncertain returns }\end{array}$ & 256 & 61 \\
\hline Total & 135 & 32.1 \\
\hline
\end{tabular}

\subsubsection{Practice of Climate Smart Practices}

Findings show that some $(65.7 \%, n=276)$ farmers attempted to practice climate smart practices (Table 3.12). However, $36.8 \%$ of the farmers abandoned the practices for various reasons, and only few (28.9\%) continued with adoption of practices.

Table 3.12: Attempted Practice of Climate Smart Practices in the study area

\begin{tabular}{lll}
\hline $\begin{array}{l}\text { Attempted practice of } \\
\text { climate smart practices }\end{array}$ & Frequency & Percentage \\
& (n) & $\%$ \\
\hline Yes & 276 & 65.7 \\
No & 144 & 34.3 \\
\hline Total & & \\
\hline
\end{tabular}

This corroborates findings by Omoro (2014) who found that several farmers abandoned green house technology even after high initial capital investment in Kisii and Nyamira Counties due to low production and sometimes total failure of the crops. According to the same study, the poor performance was attributed to lack of knowledge and skill (Omoro, 2014).

\subsubsection{Policy Framework and Adoption of Climate Smart Practices}

Analysis of National and country documents showed lack of sector specific climate risk management plans, due to limited or lack of awareness concerning climate change effects. Similarly, while there were provisions that support adoption of climate smart practices, they were inconsistent, weak and are faced with implementation and enforcement challenges. Similarly, regional government apparently doesn't seem to adhere to the provisions, because of weak national and county government linkage. During Focus Group Discussions, the agriculture sector service providers acknowledged existence of weak policies and poor implementation due to financial constraints. They contended that policies do not adequately address environmental concerns; they also indicated weak research-extension-farmers and regional- National government linkages. This is supported by Maina et al. (2013) who found that existing lack of policy coherence posed the risk of weakening long term policy goals on climate change and Agriculture.

\subsection{Climate and Weather Information Dissemination and its Influence on Adoption of Climate Smart Practices among Small Scale Farmers}

\subsubsection{Extent of Climate and Weather Information Dissemination in the study area}

Findings of this study revealed very low $(23.3 \%)$ access to weather and climate information disseminated in the form of agro weather advisories. Majority (76.7\%) of the respondents indicated they were oblivious of the information that included technical advises on appropriate practices undertaken to ensure resilience to climate and seasonal weather shocks.

This revealed the low extent of dissemination of agro weather advisories, and hence the high vulnerability among farmers to climate change risks in the study area. The low access was as a result of weak and limited dissemination of agro weather advisories (Key Informants and FGDs). These findings were consistent with Harvey et al. (2009), who expressed concern over inadequate sharing of climate information in Africa, which had led to limited access to climate information particularly among small scale farmers. These results were similar to the outcome of a survey conducted by Jha et al.(2012) in Bundelkhand region of Central India which showed that farmers relied mostly on local and traditional sources of information to make their farming decisions. Only $15 \%$ 
of the respondents during the survey indicated access to agro meteorological information in this region of India. This affirms low access of agro meteorological information among farmers in developing countries, in spite of the high vulnerabilities to the vagaries of weather.

\subsubsection{Channels used in Dissemination of Agro Climate and Weather information to Farmers}

From the findings it was explicit, the main mode of communication that reached a wider audience among respondents with agro weather advisories was both electronic (TV, Radio) and print media (Newspapers) (42\%). This revealed that the most effective way that agro weather information can be disseminated in the study area was through the media, particularly through the local vernacular FM radios, which have a wide audience among the rural farmers. This corroborates WMO (2009) and Weiss et al. (2000) assertion that television and radio remains the most reliable means of dissemination of agro weather information among small scale farmers, and particularly when broadcasted in the local languages.

Other ways through which agro weather information was provided to farmers included barazas $(2 \%)$, extension service (13\%), field days (3\%) and farmer groups (1\%) but to a very limited extent. Similarly, there was a significant portion (39\%) of farmers who were not accessible to any channel of dissemination. These results indicated significant shortcomings in dissemination of agro weather information through extension services and farmer organizations, which once strengthened would lead to enhanced access of agro weather information among farmers. These results were also in agreement with a study carried out by Zendera (2011) among smallholder farmers in Perkerra and Lari-Wendani Irrigation schemes in Kenya. The study revealed that $98 \%$ of the farmers received agro meteorological information through radio, but to a very limited extent through bulletins, mobile phone, internet, agricultural extension services and barazas.

\subsubsection{Knowledge of application of Agro -Climate and Weather Information}

Only $11 \%$ of the respondents had the understanding on the working knowledge of agro weather information, while majority (84\%) indicated lack of knowledge. This is a sharp decline from the proportion that indicated awareness $(23.3 \%)$. This shows that even though some farmers have awareness, they lack the how and why knowledge with respect to agro weather advisories considered vital in influencing farmers decisions (Roger, 2003).

The low knowledge level was attributed to low access to climate information and lack of training on interpretation of the information in terms of management strategies to be undertaken according to key informants $\&$ focus group discussions. This is in congruence with Chamboko et al. (2008), who found similar results in his study in Zimbabwe. As recourse participatory process involving farmers, traditional forecasters, extension service and meteorological services providers has been suggested (WMO, 2012) and is currently being promoted by ASDSP in all 47 counties. This approach referred to as Participatory Scenario Planning (PSP) ensures sharing and interpretation of weather and climate information for enhanced understanding and application by all agricultural stakeholders including farmers.

\subsubsection{Extent of Weather and Climate Information Dissemination and Adoption of Climate Smart Practices}

Adoption of climate smart practices in response to weather and climate information revealed positive correlation. Apparently, adoption was low and ranged between (1.2\% to 21.9\%) (Table 4.58). The low adoption of practices was a consequence of limited access to the information among farmers. According to Deressa et al. (2009) availing climate information enhanced the adoption of appropriate crop varieties by $17.6 \%$ in the Nile basin of Ethiopia.

Findings similarly showed varying levels of adoption of climate practices in response to agro weather information. For instance some practices ranked highly among farmers compared to others i.e. use of organic manure $(21.9 \%)$, agroforestry (19.28\%), mixed cropping (17.3\%) and rain water harvesting $(17.1 \%)$ ranked relatively higher in terms of adoption. While adoption of index-based agricultural insurance (1.2\%), silage making (2.14\%), preservation of hay $(2.85 \%)$, improved fallowing $(3.3 \%, n=14)$ was quite low (Table 3.13$)$. The difference was likely attributed to low awareness of practices such as index based insurance, limited livestock rearing and low awareness of climate change phenomenon among some farmers. This shows the need for simultaneous access of agro weather information with appropriate climate smart practices knowledge among farmers. 
Table 3.13: Intensity of Adoption of Climate Smart Practices in Response to Weather and Climate Information Dissemination in the study area.

\section{Climate smart practices}

Appropriate crop and livestock varieties

Mixed cropping

Integrated crop and livestock systems

Improved fallowing

Agroforestry

Green house technology

Intercropping with legumes and fertilizer fodder crops

Crop rotation

Rain water harvesting

Irrigation

Construction of water retention structures

Biogas production

Preservation of hay

Planting of cover crops

Pasture management e.g. controlled grazing, improved

forage varieties, deferment, Reseeding, control of weeds

Silage making

Use of organic manure

Index-based agricultural insurance

Feed management to reduce methane emissions

Farm-specific nutrient management $\&$ precise (micro-

dose) fertilizer application

\begin{tabular}{|c|c|}
\hline \multicolumn{2}{|c|}{ Intensity of adoption } \\
\hline $\begin{array}{l}\text { Frequency } \\
\text { (n) }\end{array}$ & $\begin{array}{l}\text { Percentage } \\
\%\end{array}$ \\
\hline 54 & 12.85 \\
\hline 73 & 17.3 \\
\hline 31 & 7.4 \\
\hline 14 & 3.3 \\
\hline 81 & 19.28 \\
\hline 24 & 5.71 \\
\hline 59 & 14.04 \\
\hline 62 & 14.76 \\
\hline 72 & 17.14 \\
\hline 26 & 6.2 \\
\hline 59 & 14.05 \\
\hline 14 & 3.3 \\
\hline 12 & 2.85 \\
\hline 36 & 8.5 \\
\hline 23 & 5.48 \\
\hline 9 & 2.14 \\
\hline 92 & 21.9 \\
\hline 5 & 1.2 \\
\hline 21 & 5 \\
\hline 33 & 7.85 \\
\hline
\end{tabular}

\section{Conclusions and Recommendations}

\subsection{Conclusions}

Based on the findings of this study, the following conclusions were made;

There was growing awareness of climate change problem among small scale farmers and emerging need for adaptation to climate change effects through adoption of climate smart practices. However, a significant proportion of farmers and district policy makers were still oblivious of the climate change challenge. Hence the limited focus on climate changes adaptation and adoption of climate smart practices. There was significant knowledge gap and low practice of climate smart practices, in spite of the positive outlook to climate smart practices attributed to collapse of extension services over the years and particularly after devolution of governance.

Adoption of climate smart practices was hampered mainly by dwindling farm sizes, limited knowledge of climate smart practices, limited outreach of weather and climate information, low financial capability and weak policy framework. While these findings affirmed the importance of access to climate and weather information in enhancing adoption of climate smart practices. Its access and its use were low and patchy.

\subsection{Recommendations}

Based on the conclusions above, the study recommends the following;

The National Government and development partners to enhance sensitization of farmers and policy makers at the Region level regarding climate change and its impacts on agriculture.

The Ministry of Agriculture, Livestock and Fisheries at both National and the Country level of should undertake capacity building and strengthening of extension service delivery to enhance awareness, skill and knowledge for adoption of climate smart practices among farmers.

The Ministry of Agriculture, Livestock and Fisheries at National and Country level to provide budgetary support and strengthen public-private partnership to leverage funds for adoption of climate smart practices. The Province Government should also set up Climate Change Unit that will target carbon related funds i.e. REDD+, CDM, adaptation fund.

The Ministry of Agriculture, Livestock and Fisheries to develop sound policy and legal framework for adoption 
of Climate Smart Practices.

The Ministry of Agriculture, Livestock and Fisheries at National and County level and Ethiopia Meteorological Services to upscale dissemination of climate information by packaging it into user friendly formats and using channels that are effective and accessible to small scale farmers.

\section{References}

Adger, W., Agrawala, S., Mirza, M., Conde, C., OBrien, K., Pulhin, J. (2007). Assesment of Adaptation Practices, Options, Constraints and Capacity. In C. O. Parry ML (Ed.), Climate change 2007: Impacts, Adaptation and Vulnerability. Contribution of Working Group 11 to the Fourth Assesment Report of the Intergovernmental Panel on Climate Change (pp. 717-743). Cambridge: Cambridge University Press.

Arbuckle, Jr, J. G., Morton, L.W., \& Hobbs, J. (2013). Farmer Beliefs and Concerns about Climate Change and Attitude toward Adaptation and Mitigation: Evidence from Iowa. Climate change, 118 (3), 551-563.

Arukulem, E.Y., Makindi, M.S., \& Obwoyere, G.O.(2015).Climate Variability and the Associated Impacts on Smallholder Agriculture in Senetwo Location, Kenya. International Journal of Science and Research(IJSR). $4(8), 845-850$.

Beddington, J., Asaduzzaman, M., Fernandez, A., Marrion G., Erda, L., et al. (2011). Achieving Food Security in the Face of Climate Change:Summary for Policy Makers from The Commission on Sustainable Agriculture and Climate Change. copenhagen, Denmark: CGIAR Research program on Climate Change, Agriculture and Food Security.

Branca, B., Tennigkeit, T., Mann, W., \& Lipper, L. (2012). Identifying Opportunities for Climate-Smart Agriculture Investments in Africa". A study for FAO program of work on Economics and Policy Innovations for Climate-smart Agriculture (EPIC). , http://www.fao.org/climatechange/climatesmart/en/. Rome: FAO.

Branca, G., McCarthy, L., \& JoleJole, M. (2011). Climate Smart Agriculture: A synthesis of Empirical Evidence of Food Security and Mitigation benefits from Improved Cropland Mnagement. Working Paper. Rome: FAO.

Bryan, E., Ringler, C.,Okoba, B., Koo, J., Herrero, M.\& Silvia, S.(2013). Can Agriculture Support Climate Change Adaptation, Greenhouse Gas Mitigation and Rural Livelihoods? Insights from Kenya. Climatic Change, 118 (2), 151-165.

Bryan, E.,Ringler, C.,Okoba, B.,Roncoli,C.,Silvestri,Silvia.\& Herrero,M.(2011).Adapting Agriculture to Climate Change in Kenya: Household and Community Strategies and Determinants. Presented at George Washington University, Washington, D.C., 19 May 2011.

CGIAR. (2009). Climate Change Agriculture and Food Security:A Strategy for Change.

CGIAR Center.

Chamboko, T., Mtambanemgwe, F., Chikowo, R., Mapfumo, P., \& Mekutia, M. (2008). Climate Change And Variability Information Access and Adaptation: The Case of Smallholder Farming Communities in Zimbabwe. pp. 110-115.

Cherotich, K., Osen, I. S., \& Omedo, B. (2012). Access to Climate Change Information and Support Services by Vulnerable groups in Semi-Arid Kenya for Adaptive Capacity Development. African Crop Sciences Journal, 20(2), 169-180.

Dooley, E., \& Chapman, S. (2014). Climate Smart Agriculture and REDD+ Implementation in Kenya. REDD+ Law Project-Briefing Paper

Dulal, H., Brodnig, J., Onoriose, C., \& Thakur, H. (2010). Capitalising on Assets; Vulnerability and Adaptation to Climate Change in Nepal. World Bank Social Development Papers No, 121.

Fanen, T. (2014). Assesing the Role of Climate Smart Agriculture in Combating Climate Change, Desertification and Improving Rural Livelihood in Northern Nigeria . African Journal of Agricultural Research, 9(15), 11801191.

FAO. (2010). Climate Smart Agriculture Policies, Practices and Financing for Food Security, Adaptation and Mitigation. United Nations. Rome Italy: Food and Agriculture Organisation.

FAO. (2013). Climate Smart Agriculture Source Book. United Nations . Rome, Italy: Food and Agriculture Organisation.

FAO.(2015). Barriers, Incentives and Benefits in the adoption of Climate Smart Agriculture: Enhancing Agricultural Mitigation Within East Africa Dairy Development project(EADD) in Kenya. Rome: FAO.

FAO. (2015). Smallholder Integrated Crop-Livestock Farming Systems: Scoping Study on Climate Smart Agriculture in Kenya. Mitigation of Climate change in Agriculture (MICCA) Programme. Background Report 8.Rome: FAO.

Fischer, G., Shah, M., Tubiello, F., \& Van Velhuizen, H. (2005). Socio-economic and Climate Change Impacts on Agriculture:An Intergrated Assesment,1990-2080. Philosophical Transaction Son Royal Society, 360 (1463), 2067-2083.

Frank, J., \& Penrose Buckley, C. (2012). Small Scale farmers and Climate Change. How Can Farmer Organisations and Fairtrade built the Adaptive Capacity of Small Holders? IIED. 
Hallam, A., Bowden, A., \& Kasprzyk, K. (2012). Agriculture and Climate Change: Evidence on Influencing Evidence on Influencing Farmer Behavior. Scottish Government Social Research.

Harvey, B., Diagne, B., Nnam, J., \& Tadege, A. (2009). Knowledge Sharing for Climate Change Adaptation in Africa: Opportunities and Challenges. Africa Adapt Guest Article,(73).

Howden, S., Soussana, J., Tubiello, F., Chhetri, N., Dunlop, M., \& Meinke, H. (2007). Adapting Agriculture to Climate Change. Retrieved July 9, 2014, from http://www.pnas.org/content/104/50/19691.full.pdf+html.xii

Howley, P., Cathal, O. D., \& Heanue, K. (2012). Factors Affecting Farmers Adoption of Agricultural Innovations:A Panel Data Analysis of the Use of Artificial Insemination among Dairy Farmers in Ireland. Journal of Agricultural Science, 4(6), 171-179.

Ifejika, S. (2010). Resilient Adaptation to Climate Change in African Agriculture. Bonn, Germany: Deutsches Institut fur Entwicklungspolitik/German Development Institute.

IFPRI.(2004). Ending Hunger in Africa: Prospects for the Small Scale Farmer. International Food Policy Research Institute, Washington DC.

IPCC. (2012). Managing the Risks of Extreme Events and Disasters to advance Climate Change Adaptation. A special Report of Working Groups I and II of the Intergovernmental Panel on Climate Change. In C. Field, T. Barros, D. Stocker, D. Qin, K. Dokken, M. Ebi, et al. (Ed.). Cambridge, UK and New York, NY, U.S.A: Cambridge University Press.

IPCC. (2014). Impacts, Adaptation and Vulnerability. Contribution of Working Group II to the Fifth Assessment Report of the Intergovernmental Panel on Climate Change. Cambridge, UK: Cambridge University press.

Kalungu, J. W., R, F. W., \& David, H. (2013). Small Holder Farmer Perception of the Impacts of Climate Change and Variability on Rainfed Agricultural Practices in Semi-Arid and Sub-humid Regions of Kenya. Journal of Environment and Earth Science, 3(7), 129-141.

Kipkoech, K.A.,Tambi.E.,\& Bangali,S.(2015). State of Knowledge on CSA in Africa: Case studies from Ethiopia, Kenya and Uganda.The Forum for Agricultural Research in Africa, ACRA, Ghana.

Kristin, E.D. (2004).Technology Dissemination among Small Scale Farmers in Meru Central District of Kenya: Impact of Group Participation. Ph.D. Dissertation Presented to the Graduate School of the University of Florida.

Kubiszewski, I., \& Cleveland, C. (2012). United Nations Conference on Environment and Development (UNCED), Rio de Janeiro, Brazil. Retrieved July 20, 2014, from http://www.eoearth.org/view/article/156773

Legesse, B., Ayele, Y., \& Bewket, W. (2012). Smallholder Farmers' Perceptions and Adaptation to Climate Variability and Climate Change in Doba District, West Hararghe, Ethiopia. Asian Journal of Empirical Research, 3(3), 251-265.

Maina, I;Newshan, A; Okoti, M.(2013). Agriculture and Climate Change in Kenya: Climate Chaos, Policy Dilemmas. Working Paper 07 .Agriculture Futures.Org.

Marques, J.M.,Bienes, R.,Cuadrado, J.,Ruiz-Colmenero,M.,Barbero-Sierra, C.\& Velasco, A.(2015). Analysing Perceptions Attitudes and Responses of Wine growers about Sustainable Land Management in Central Spain. Land Degradation \& Degradation. 26(5), 458-467.

Mburu, B.K., Kungu, J.B. (2015). Climate Change Adaptation Strategies by Small -Scale Farmers in Yatta District, Kenya. African Journal of Environmental Science and Technology, 9(9), 712-722.

Mburu, B., Muriuki, J., \& Kungu, J. (2014). Effects of Climate variability and Change on Household Food Sufficiency among Small Scale Farmers of Yatta District, Kenya. Journal of Environment, 3(2), 19-27.

Mburu, K. (2013). Effects of Climate Variability and Change on Dry land Agriculture and the Adaptation strategies by Small Scale Farmers in Yata District. PhD Thesis. Kenyatta University.

McCarthy, N., Winters, P., Linares, \& Essam, T. (2012). Indicators to Assess the Effectiveness of Climate Change Projects :Impact-Evaluation Guideliness. Inter-American Development Bank.

McCarthy, N., Lipper, L. \& Branca G. (2011). Climate Smart Agriculture: Smallholder Adoption and Implications for climate change Adaptation and Mitigation. Mitigation of Climate change in Agriculture (MICCA) Programme, FAO. Rome.

Mendelsohn, R., A.Dinar, \& A.Dalfelt. (2000b). Climate Change Impacts on African Agriculture. Preliminary Analysis prepared for the World Bank. Washington, District of Columbia.

Mendelsohn, R., W.Morrison, M.E.Schlesinger, \& N.G.Androva. (2000a). Country-Specific Market Impacts from Climate Change. Climatic Change, 45(3-4), 553-569.

MENR. (2010). National Climate Change Response Strategy. Nairobi: Ministry of Environment and Natural Resources .

MENR. (2013). National Climate Change Action Plan (2013-2017. Nairobi: Ministry of Environment and Natural resources. 